\title{
Massif forestier de Bellême
}

Fabrice Morand

\section{OpenEdition \\ Journals}

Édition électronique

URL : http://journals.openedition.org/adlfi/7416

ISSN : 2114-0502

Éditeur

Ministère de la culture

Référence électronique

Fabrice Morand, " Massif forestier de Bellême », ADLFI. Archéologie de la France - Informations [En ligne], Basse-Normandie, mis en ligne le 01 mars 2007, consulté le 01 mai 2019. URL : http:// journals.openedition.org/adlfi/7416

Ce document a été généré automatiquement le 1 mai 2019.

(c) Ministère de la Culture et de la Communication, CNRS 


\title{
Massif forestier de Bellême
}

\author{
Fabrice Morand
}

Date de l'opération : 2007 (PR)

Inventeur(s) : Morand Fabrice (BEN)

La mission de prospection a été renouvelée pour l'année 2007 afin de poursuivre la recherche des indices de structures anthropiques conservées en élévation. Nous avons obtenu des résultats très intéressants en ce qui concerne les enceintes fossoyées repérées. Elles sont au nombre de six (trois non connues sur la carte archéologique), et sont situées sur la ligne de crête de la forêt de Bellême. Les distances entre deux enceintes sont variables : $2000 \mathrm{~m}$ entre le camp des Fourneaux et le camp de César, $500 \mathrm{~m}$ entre le camp de César et le camp du Paty, $1250 \mathrm{~m}$ entre le camp du Paty et le camp du Châtelier, $1850 \mathrm{~m}$ entre le camp du Châtelier et le camp des Bruyères, et enfin $700 \mathrm{~m}$ entre le camp des Bruyères et le camp de la Croix aux Marchands (Fig. $\mathrm{n}^{\circ} 1$ : Camp de César).

Nous avons également constaté un nombre important de ferriers (27) pour lesquels la majorité des déchets de réduction du fer sont des scories de type "plaque à cordon». Ils sont en majorité situés sur des zones à fosses d'extractions, sorte de carrières à ciel ouvert plus ou moins importantes. Il est donc possible que la réduction du fer se soit faite à proximité immédiate du minerai. La plupart des ferriers contenant des scories de type « plaque à cordon » ont leurs ateliers à proximité, bâtiments ou habitats antiques ou plus récents. Les sites à ferriers sont pour la plupart desservis par des chemins cavés simples ou doubles, mais il est pour l'instant difficile d'en proposer une chronologie.

De nombreuses traces de talus, de fosses, de fosses d'extractions, de tertres (tumulus présumés ?), ont été repérées pour lesquelles la chronologie est incertaine.

D'autres marques, qui font aussi partie de l'histoire de la forêt de Bellême, sont liées à la seconde guerre mondiale (treize casemates sur la ligne allemande, repérées en 2006, trois autres retrouvées sur la commune de La Perrière en 2007).

Pour une prospection optimisée, il nous a semblé important d'effectuer en parallèle une recherche aux archives de l'Orne et aux Archives nationales. Les archives de l'Orne 
disposent de documents parchemins anciens et la plus ancienne mention de la forêt est datée de 1217, rien n'indiquant cependant que la forêt, à cette période, occupait la même superficie que celle d'aujourd'hui. Il existe un document encore plus ancien, une charte de Hugues de Roçé, qui cite le Moulin de Butin en 1050, situé en lisière de la forêt, mais malgré les donations citées en limite de la forêt de Bellême et la ville de Bellême, aucune indication écrite ne donne l'indice qu'il y avait une forêt.

La plupart des documents étudiés sont datés de 1352, 1476, 1536, 1768, et concernent les religieux des différents prieurés en limite de la forêt, Saint-Martin-du-Vieux-Bellême, Chêne-Galon, Saint-Léonard et La Chaise. Il est question du droit d'usage du bois de construction ou de chauffage pour les religieux, ainsi que le droit de faire paitre leurs bêtes. Mais aucun document n'indique une éventuelle industrie du fer.

Les recherches aux Archives nationales ont donné des résultats plus modestes. Les documents consultés concernaient en majorité la réformation forestière, ainsi que la déclaration des revenus temporels des prieurés qui stipulent les droits d'usages de la forêt de Bellême.

Après ces recherches, des indices laissent à penser que le bois est effectivement géré depuis le XII ${ }^{\mathrm{e}}$ s., mais aucun document n'évoque l'usage de bois pour la réduction du fer, de carrières à ciel ouvert, ou d'habitats. On peut penser, au vu des indices anthropiques localisés lors des prospections 2006 et 2007, que la forêt de Bellême est une forêt primaire, antérieure au Moyen Âge, dont les usages et la configuration devaient être très différents de ceux que nous connaissons aujourd'hui.

MORAND Fabrice

\section{ANNEXES}


Fig. $\mathrm{n}^{\circ} 1$ : Camp de César

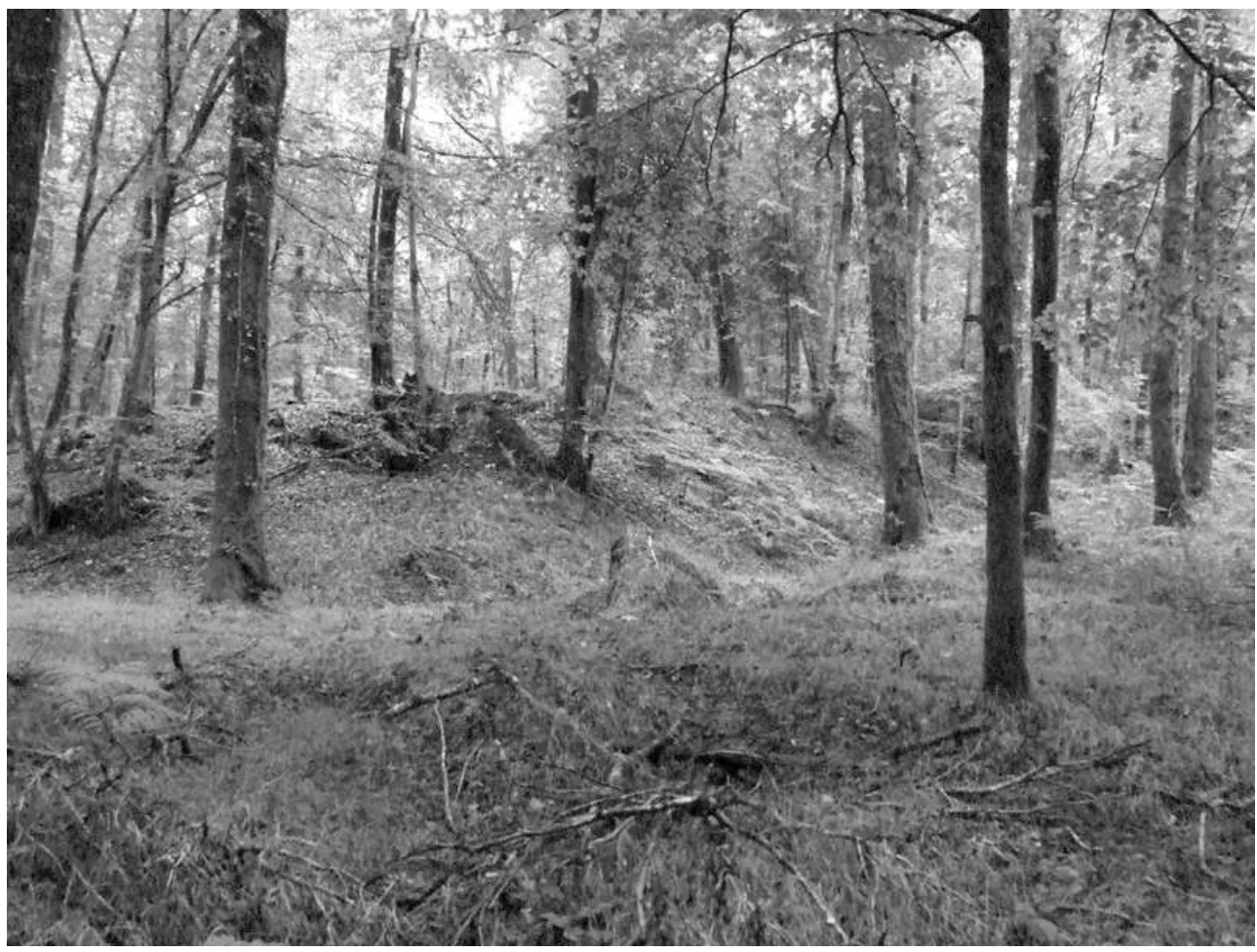

Auteur(s) : Morand, Fabrice (BEN). Crédits : Morand, Fabrice (2007)

\section{INDEX}

operation Prospection (PR)

Thèmes : acquisition de ressource naturelle, archive départementale, droit coutumier, enceinte, ferrier, fossé, guerre, minerai, parchemin, prieuré, route, scories, sources écrites, tumulus

Index chronologique : ép. contemporaine, Moyen Âge*

Index géographique : Basse-Normandie, Orne (61), Bellême

\section{AUTEURS}

\section{FABRICE MORAND}

BEN 